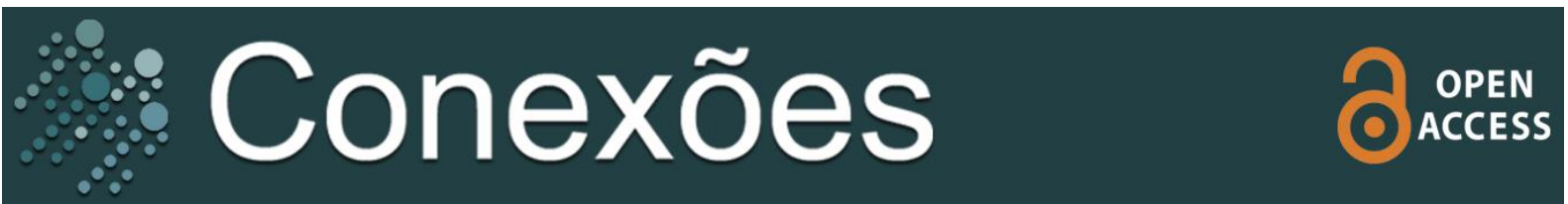

Artigo Original

\title{
Os programas de esporte educacional nos governos Lula e Dilma: avanços, limites e anacronismos
}

\author{
Educational sports programs in the Lula and Dilma administrations: \\ advances, limits and anachronisms
}

\section{Programas educativos deportivos en las administraciones de Lula y Dilma: avances, límites y anacronismos}

\author{
Nadson Santana Reis ${ }^{1}$ \\ Pedro Fernando Avalone de Athayde ${ }^{1}$ \\ Fernando Mascarenhas ${ }^{1}$
}

\begin{abstract}
RESUMO
Objetivo: O presente estudo buscou analisar o modelo técnico-operacional dos programas de esporte educacional implementados pelos Governos Lula e Dilma entre os anos de 2003 e 2016. Método: Para tanto, analisou-se as orientações técnico-operacionais do Programa Segundo Tempo, da Ação Descoberta do Talento Esportivo e do Projeto Esporte Brasil, bem como do Programa Esporte da Escola. A pesquisa, de natureza documental, avaliou materiais com orientações pedagógicas, manuais, cartilhas educativas, instrumentos de avaliação e de organização didática das ações em análise. Resultados: Os resultados indicam avanços, como a defesa da democratização do esporte e de seu trato didáticopedagógico pautado na inclusão e ludicidade; limites, cuja maior expressão é a ênfase no paradigma esportivo e da aptidão física/aprendizagem motora; e anacronismos, que implicam o reclame da Educação Física e da escola na seleção, identificação, orientação e formação de novos talentos. Considerações finais: As considerações, nessa direção, apontam para a ausência de alinhamento e definição quanto à linha de ação governamental que, não obstante, acaba por oscilar entre proposições divergentes, contraditórias e antagônicas, inclusive dentro de um mesmo programa.
\end{abstract}

Palavras-chave: Políticas públicas. Esportes. Esporte Educacional.

\footnotetext{
${ }^{1}$ Universidade de Brasília, Faculdade de Educação Física, Grupo de Pesquisa e Formação Sociocrítica em Educação Física, Esporte e Lazer (Avante/UnB), Brasília-DF, Brasil.
}

Correspondência:

Nadson Santana Reis. Rua Pedro Calmon, 451, Bairro Paraíso, Guanambi - BA, CEP 46430-000.

E-mail: nadsonsr@hotmail.com 


\begin{abstract}
Objective: The present study sought to analyze the technical-operational model of educational sport programs implemented by the Lula and Dilma Governments between 2003 and 2016. Methods: For this purpose, the technical-operational guidelines of the Programa Segundo Tempo, of the Discovery of Talent Action were analyzed. Sport and the Esporte Brasil Project, as well as the Esporte da Escola Program. The research, of a documentary nature, evaluated materials with pedagogical guidelines, manuals, educational booklets, assessment instruments and didactic organization of the actions under analysis. Results: The results indicate advances, such as the defense of the democratization of sport and its didactic-pedagogical approach based on inclusion and playfulness; limits, whose greatest expression is the emphasis on the sports and physical fitness/motor learning paradigm; and anachronisms, which imply the claim of Physical Education and the school in the selection, identification, orientation and training of new talents. Final considerations: Considerations in this direction point to the lack of alignment and definition regarding the line of government action which, nevertheless, ends up oscillating between divergent, contradictory and antagonistic propositions, even within the same program.
\end{abstract}

Keywords: Public policy. Sports. Educational Sport.

\title{
RESUMEN
}

Objetivo: I presente estudio buscó analizar el modelo técnico-operativo de los programas educativos deportivos implementados por los Gobiernos de Lula y Dilma entre 2003 y 2016. Método: Para ello, se analizaron los lineamientos técnico-operativos del Programa Segundo Tempo, del Descubrimiento de la Acción del Talento. El Deporte y el Proyecto Esporte Brasil, así como el Programa Esporte da Escola. La investigación, de carácter documental, evaluó materiales con lineamientos pedagógicos, manuales, folletos educativos, instrumentos de evaluación y organización didáctica de las acciones bajo análisis. Resultados: Los resultados indican avances, como la defensa de la democratización del deporte y su enfoque didáctico-pedagógico basado en la inclusión y la alegría; límites, cuya mayor expresión es el énfasis en el paradigma del deporte y la aptitud física / aprendizaje motor; y anacronismos, que implican el reclamo de la Educación Física y la escuela en la selección, identificación, orientación y formación de nuevos talentos. Consideraciones finales: Consideraciones en esta dirección apuntan a la falta de alineación y definición de la línea de acción del gobierno que, sin embargo, termina oscilando entre planteamientos divergentes, contradictorios y antagónicos, incluso dentro de un mismo programa.

Palabras Clave: Política pública. Deportes. Deporte educativo. 


\section{INTRODUÇÃO}

O esporte educacional, dimensão do esporte praticado nos sistemas de ensino e em formas assistemáticas de educação com vistas ao desenvolvimento integral e à formação cidadã, conforme aponta o Decreto $n^{\circ}$. 7.984/2013 que alterou a Lei Pelé ( $n^{\circ}$. 9.615/1998), passou a ocupar, na sequência dos anos 2000 , lugar de destaque no conjunto das políticas de esporte desenvolvidas pelo Estado brasileiro.

Essa inflexão ocorreu, sobretudo, a partir do fracasso da participação brasileira nas Olímpiadas de Sidney em 2000. Assim, a partir daquele momento "[...] desencadeou-se um movimento de revalorização das práticas esportivas nas escolas, seja por meio da disciplina curricular Educação Física, seja por meio de programas específicos, ou ainda com a retomada das competições estudantis". (OLIVEIRA, 2009, p. 9). Tal fato destravou um movimento amplo de revalorização das práticas esportivas nas escolas, especialmente a partir da ambição por identificação e seleção de novos talentos esportivos já na educação básica.

Assim, a inserção do país na rota dos megaeventos esportivos iniciada, sobretudo, em 2007, com os Jogos Pan-americanos, impulsionou ainda mais esse movimento. A "nova" agenda esportiva - colonizada e submissa aos grandes eventos, conforme análises de Mascarenhas (2012) e Bracht e Almeida (2013) - buscou instrumentalizar a política de esporte educacional com vistas a alavancar o esporte de representação nacional.

Isso ocorreu porque a operacionalização dessa agenda esportiva cobrou ações de legitimação. O que se estabeleceu, segundo Mascarenhas (2012), a partir do ufanismo patriótico mobilizado pelos resultados esportivos e pela criação do herói esportivo nacional. Fatores que justificaram a demanda crescente por melhores resultados e, também, por novos talentos.

Para Pires e Silveira (2007), mais do que a perspectiva de transformar a escola numa fábrica de atletas, onde o talento esportivo seria descoberto, tal pretexto representou a desconsideração de toda a produção teórica - de natureza crítica - das Ciências do Esporte dos últimos anos. Tornando-as irrelevantes para se pensar o esporte e seu papel na formação de crianças e jovens.

Nesses termos, esse estudo busca analisar as orientações técnicooperacionais dos programas que compõe a política de esporte educacional, organizada entre 2003 e 2016, pelo Governo Federal (Lula e Dilma). Conforme alertou Libâneo (1985), tais orientações refletem a direção epistemológica e, ademais, informam sobre os requisitos para selecionar, organizar, sistematizar e tratar os conteúdos no âmbito dessas políticas. 
Assim, a justificativa para esse estudo decorre da necessidade de se entender os motivos, os interesses e os papéis assumidos por esses programas no contexto dos megaeventos esportivos no país. Isso porque, a política de esporte, um tipo particular de política social, resulta de processos contraditórios e multicausais que atendem a várias finalidades, que precisam ser conhecidos, interpretados e avaliados.

Além disso, a importância deste trabalho reside na necessidade de avaliação crítica a respeito das diretrizes teórico-metodológicas que orientam a política esportiva em tela. Uma questão relativamente ausente na literatura especializada, a julgar pelo estudo de Reis et al. (2015), que, no âmbito de uma revisão sistemática, indicou - desde a edição da Lei Pelé, em 1998, até o Decreto $7.984 / 2013$ - a carência de pesquisas sobre as orientações didáticometodológicas da política esportiva educacional brasileira.

Contudo, desde a indicação da necessidade de revigoramento da produção científica sobre o tema (REIS et al., 2015), outros trabalhos foram apresentados à comunidade acadêmica. Nesse interim, sem a pretensão de uma discussão abrangente, é oportuno considerar no escopo deste texto os esforços de Santos e Nogueira (2016), que assinalaram a necessidade de descentralização e coordenação/cooperação entre os governos federal e municipal na condução das políticas em discussão; além, é claro, das observações de Kravchychyn e Oliveira (2016), que sinalizaram as ações pedagógicas na dependência do direcionamento de gestão, da relação teoria-prática e do trabalho coletivo.

Ademais, é importante destacar as contribuições de Paes e Amaral (2017), que, avaliando os impactos dos Jogos Olímpicos, sinalizaram a reedição da ideia de pirâmide esportiva no contexto nacional; e as análises de Rottmann e Ratto (2017), que colocaram o esporte educacional como ferramenta fundamental à educação, desde que voltado à formação de crianças e jovens conscientes de seus papéis e responsabilidades sociais. Cabe destacar, além disso, o trabalho de Machado et al. (2017), que levantou a incorporação do esporte educacional no cenário político brasileiro; e as elaborações de Carneiro, Mascarenhas e Matias (2017), cujas considerações asseveram pela falta de infraestrutura adequada (quadras esportivas) como um dos principais limites para o desenvolvimento da política em análise. Há, além do exposto, estudos sobre financiamento que assinalam o esporte educacional como uma não prioridade no âmbito da política esportiva nacional. (CASTRO; SCARPIN; SOUZA, 2017).

Merecem atenção, ainda, a pesquisa de Anversa et al. (2018), que pautou a questão da formação continuada e sua implicação na ação pedagógica; as formulações de Souza (2019), que sinalizaram para um certo hibridismo negativo na prática esportiva, em que o esporte educacional acaba colonizado pelo esporte competitivo; e, por fim, a investigação de Silva et al. (2020), que, 
em estudo sobre a formação continuada e o desenvolvimento de princípios pedagógicos, argumentaram pela necessidade de conjugação destas duas ações, já que a operacionalização das diretrizes pedagógicas - inclusão de todos, respeito à diversidade, educação integral, autonomia e construção coletiva depende do refazimento dos agentes sociais e políticos diretamente implicados.

\section{Delineamento Metodológico}

Os programas objetos de análise desse estudo, como já anunciado, foram implementados pelos Governos Lula e Dilma entre 2003 e 2016. A seleção dos programas esteve condicionada, entretanto, ao oferecimento de orientações didático-pedagógicas sistematizadas a seus agentes culturais. Isto é, a disponibilização de diretrizes para a organização e o desenvolvimento de ações voltadas ao trato didático-pedagógico do esporte no âmbito dos programas de esporte educacional.

Tal critério levou, portanto, à análise de quatro programas específicos, quais sejam: o Programa Segundo Tempo, a Ação Descoberta do Talento Esportivo, o Projeto Esporte Brasil e o Programa Esporte da Escola. O programa Forças no Esporte, os Jogos Escolares Brasileiros e o Atleta na Escola não foram analisados, uma vez que, embora oferecessem diretrizes normativo-operacionais, tais políticas não disponibilizaram orientações didático-pedagógicas sistematizadas.

Desse modo, a pesquisa, de natureza documental e qualitativa, reuniu um conjunto de fontes de consulta que envolveu documentos oficiais, dispositivos legais e políticos que buscaram traçar e anunciar as diretrizes organizacionais e, sobretudo, as orientações pedagógicas para o desenvolvimento e implementação dos programas em avaliação. Esses documentos incluíram a Cartilha Descoberta do Talento Esportivo; a Portaria Interministerial no 17 de 2007; o Material didático para o processo de capacitação do Programa Segundo Tempo; o Programa Mais Educação: passo a passo; o Programa Segundo Tempo: Diretrizes; e o Manual de orientações Esporte na Escola.

As informações coletadas, dado o propósito deste trabalho, foram analisadas tendo como horizonte o processo de ensino do esporte no contexto da política esportiva de conteúdo educacional. Para tanto, a aludida análise, delineada a partir do conceito de política social (BEHRING; BOSCHETTI, 2011), buscou desvelar as aproximações, contradições e imbricações entre as determinações legais e as orientações didático-pedagógicas para sua operacionalização (BOSCHETTI, 2009). Em outros termos, o estudo procurou verificar o conteúdo das orientações pedagógicas que estruturam a ação da política social e, de modo consequente, confrontá-lo com os princípios da democratização e universalização do esporte, bem como com a premissa da justiça social, que, em verdade, constituem os 
parâmetros/indicadores para a avaliação dos avanços, dos limites (e dos anacronismos) aqui apresentados.

\section{RESUltados e Discussão}

\section{O Programa Segundo Tempo (PST)}

O Programa Segundo Tempo (PST) surgiu em 2003 a partir dos programas "Esporte na Escola" e "Esporte Solidário". Assim, o PST aglutinou, ao menos inicialmente, ações direcionadas a alunos de instituições públicas em comunidades marcadas por alto risco e vulnerabilidade social.

O programa, nesse sentido, não assumiu declaradamente o objetivo de identificar, selecionar e/ou encaminhar talentos esportivos, discurso comumente encontrado em ações relacionados ao esporte educacional. Suas diretrizes conceituais continham, inclusive, uma crítica a essa perspectiva. Perim e Oliveira (2009, p. 25), por exemplo, argumentam que, ao programa, não cabia a ideia de "caça talentos", pois isso representaria a negação do presente da infância. Para eles, fundamental seria "[...] considerar os interesses diversificados das crianças, dos adolescentes e dos jovens pelo esporte, inclusive no sentido de que muitos não têm ambições esportivas no sentido profissional, por exemplo".

Dessa maneira, a responsabilidade do PST estava circunscrita, na avaliação de Greco e Silva (2008, p. 90), à capacitação de seus participantes de forma ampla, geral e sem especializações em uma modalidade esportiva específica. Cabendo, então, ao programa capacitar crianças e jovens para, por exemplo, decidir qual a forma de manifestação do esporte experimentaria na idade adulta.

Dessa feita, o PST enfatizava aquilo que - em princípio - estava assegurado nos objetivos de seu antecessor - o Programa Esporte na Escola. Sobretudo quando destacava o vínculo entre esporte e educação e, também, à alardeada possibilidade de atuar como coadjuvante na formação da personalidade da criança e do adolescente em situação de risco e vulnerabilidade social. (BRACHT; ALMEIDA, 2013).

Entretanto, a despeito disso, o programa não representou uma proposta diferente daquilo que, historicamente, vinham pautando as ações do Estado no campo esportivo. Esse argumento encontra fundamento na análise dos conteúdos, das estratégias e da estrutura pedagógica que sustentam a proposta de ensino do esporte no PST.

Greco, Conti e Morales (2013), que participam da organização das orientações pedagógicas do programa, defendem, por exemplo, uma estrutura pedagógica norteada por dois princípios básicos: 1) jogar para aprender; e 2) 
aprender jogando. Tais elementos, segundo os autores, se desdobrariam no conhecimento do "saber o que fazer" (conhecimento declarativo) e, ao mesmo tempo, "o saber como fazer" (conhecimento processual). Ambos, complementares no processo de apreensão do esporte, resultariam em aprendizagem tática (saber o que fazer) e aprendizagem motora (saber fazer).

Greco, Silva e Santos (2009, p. 169) justificam o referido modelo a partir da necessidade de um ensino pautado na organização pedagógica consciente, em detrimento daquilo que chamou de "prática inconsequente". Assim, com ênfase declarada nos esportes coletivos, o programa propôs um modelo de iniciação esportiva que, na avaliação de Greco e Silva (2008, p. 89), contemplava a noção de processo e pautava-se pela premissa que busca evitar "[...] tanto a mecanização e repetição analítica de atividades, com ênfase nas técnicas esportivas com base em modelos do adulto, do campeão, quanto à especialização precoce".

Tal modelo, contudo, representaria "[...] uma sequência metodológica caracterizada por uma cronologia, na forma de um A-B-C dos conteúdos. Inicia-se a sequência com a aprendizagem e se constroem as bases para o treinamento". (GRECO; SILVA; SANTOS, 2009, p. 170). Dessa maneira, tal modelo de formação envolveria, primeiramente, capacidades táticas básicas; jogos, desenvolvimento, inteligência e criatividade, além das estruturas funcionais - sequência A. Num segundo momento, as capacidades coordenativas e as habilidades técnicas sequência $B$. Por fim, na sequência $C$, o treinamento tático e técnico e 0 treinamento integrado - físico, físico-tático, físico-técnico-tático. (GRECO; SILVA, 2008).

Ademais, Greco e Silva (2008) previam a realização das atividades pedagógicas do PST circunscritas nas sequências de conteúdo $A$ e $B$. $A$ operacionalização dos conteúdos C estaria, em sua avaliação, voltada somente àqueles que optassem por integrar programas de treinamento esportivo.

Tal observação, todavia, não foi suficiente para conter o hiato latente entre o discurso funcionalista/utilitarista do esporte - presente no próprio programa - e o conteúdo do modelo A-B-C que segue centrado, irrefutavelmente, aos saberes técnico e tático. Ademais, tal estrutura não foi capaz de romper com um modelo de formação esportiva que presume a fragmentação dos vários fatores do rendimento (motor, técnico, tático) para, posteriormente, serem integrados à situação de jogo.

Esse modelo de formação/iniciação esportiva está dentro do Sistema de Aprendizagem e Desenvolvimento Esportivo (SADE), o qual reúne, segundo Greco, Silva e Santos (2009), três estruturas, a saber: estrutura substantiva, temporal e metodológica. A primeira é constituída pelo conjunto de capacidades inerentes ao rendimento esportivo (biotipológicas, motoras, táticas, técnicas, psicológicas e 
socioambientais). A segunda envolve as etapas e fases do desenvolvimento das capacidades ao longo do desenvolvimento humano. A última, por sua vez, busca conectar as duas primeiras por meio de processos de ensino-aprendizagem, com uma sequência pré-estabelecida - da aprendizagem (tática e motora) ao treinamento (tático e técnico), do jogar para aprender e do aprender jogando.

A proposta de iniciação esportiva em evidência não representa, pois, uma ruptura com as principais referências dos tradicionais arquétipos de formação esportiva. Isso porque conserva elementos há muito presente na relação/tensão entre esporte e escola, qual seja: a centralidade do paradigma da aprendizagem motora e da aptidão física e esportiva na organização do processo de apropriação do esporte. O que leva, consequentemente, à primazia do aspecto biológico e, de igual modo, a equívocos teóricos irremediáveis aos demais aspectos que caracterizam o movimento humano. (CASTELLANI FILHO, 2010).

Ademais, tal orientação configura uma substantiva e incorrigível subordinação do PST e, por conseguinte, do esporte educacional à instituição esportiva. Isso porque, o princípio do rendimento físico-esportivo constitui eixo norteador básico. Aspecto que, não obstante, representa uma incongruência substantiva entre o modelo teórico-conceitual e sua correspondente proposta técnico-operacional que, pelo exposto, está centrada - exclusivamente - nos paradigmas da aptidão física e esportiva.

Além disso, ao fazer tal opção, o programa desconsiderou a pertinência e desvalorizou o universo de significados que o esporte possui no âmbito da sociedade contemporânea, bem como negligenciou sua importância na construção da existência humana.

\section{Ação Descoberta do talento Esportivo e Projeto Esporte Brasil (PROESP- BR)}

A Secretaria Nacional de Esporte de Alto Rendimento, órgão do antigo Ministério do Esporte, ambicionando ampliar os resultados esportivos do país, mobilizou esforços no sentido de atrair, identificar e fomentar a busca por novos talentos. Nessa direção, a Ação Descoberta do Talento Esportivo foi lançada, em 2004, ao lado do Projeto Esporte Brasil (PROESP-BR).

As duas iniciativas, por seu turno, buscavam identificar adolescentes e jovens, em idade escolar, que apresentassem níveis de desempenho motor superior à média da população. Dessa maneira, os dois programas procuravam identificar talentos com a finalidade última de aumentar e dar qualidade à base esportiva nacional.

Assim, as metas da primeira iniciativa se circunscreviam a necessidade de avaliar dois milhões de estudantes entre 10 e 15 anos e de descobrir 40 mil 
talentos esportivos para, posteriormente, disponibilizá-los para encaminhamento no rendimento.

A operacionalização da ação previa, ainda, duas etapas distintas e complementares a serem realizadas anualmente: o Dia da Descoberta do Talento Esportivo; e o Talento Esportivo na Escola. A primeira, por sua vez, supunha a consumação de um evento festivo, realizados nas capitais, em espaços públicos, com a promessa de avaliar 100 mil estudantes. A segunda, de outro modo, seria desenvolvida nas escolas, especificamente no tempo/espaço das aulas de Educação Física.

A avaliação seria desenvolvida - em ambos os casos - por professores e/ou estudantes de Instituição de Ensino Superior (IES) treinados com base no protocolo de avaliação do Projeto Esporte Brasil desenvolvido pela rede CENESPUFRGS. Os testes que compõem esse protocolo envolveram variáveis como massa corporal (peso), estatura, envergadura, Índice de Massa Corporal (IMC), flexibilidade, força-resistência abdominal, força de membros inferiores e superiores, agilidade, velocidade e resistência aeróbia. As informações coletadas a partir desse protocolo, nas duas fases, seriam incluídas num banco de dados do Ministério do Esporte. No entanto, àqueles estudantes com potencial para o alto rendimento seriam deslocados para o chamado Banco de Talentos.

Para tanto, a metodologia da ação previa: capacitação de Recursos Humanos; execução das avaliações; lançamento dos resultados no banco de dados e comparação com os parâmetros de atletas de alto rendimento; inserção dos melhores resultados no Banco de Talentos; e, por fim, a disponibilização do material às entidades de administração e de prática esportiva, bem como a outras instituições interessadas no desenvolvimento desses talentos. (GAYA, [ca.2002]).

Ainda sobre a avaliação, é imprescindível destacar que a bateria de testes que compõe o protocolo desenvolvido pela Rede CENESP-UFRGS para o Projeto Esporte Brasil acompanhava, segundo Adroaldo Gaya, a proposta do Programa Nacional de Identificação de Talentos Esportivos do Instituto Australiano de Esportes (GAYA, [ca.2002]).

É necessário destacar, então, que tanto a ação Descoberta do Talento Esportivo, quanto o Projeto Esporte Brasil argumentam em favor da participação da Educação Física Escolar no fomento ao acesso de crianças e adolescente às práticas esportivas formais de rendimento. Para tanto, tais ações atribuíam à Educação Física a responsabilidade por delinear o perfil somatomotor, os hábitos de vida e os fatores de aptidão motora em crianças e adolescentes, tendo em vista referenciar a construção de políticas para a Educação Física e para o esporte no país. (GAYA, [ca.2002]).

Como se vê, as duas iniciativas em destaque não hesitam em instrumentalizar a Educação Física Escolar a partir do referencial das ciências 
biológicas para desempenhar o papel de identificar potenciais talentos. A justificativa, para isso, perpassa os exemplos bem-sucedidos das grandes potências esportivas.

Muito embora, as iniciativas não indiquem a Educação Física como responsável direta pela formação/treinamento esportivo, não é pequena a ingerência no sentido de colocá-la como corresponsável pela criação de um banco de dados, cujo princípio último é a classificação e categorização dos estudantes por desempenho/aptidão física e esportiva - o que já foi avaliado como nocivo ao processo de apreensão e avaliação dos elementos da cultura esportiva na educação formal. (SOARES et al., 1992).

O que está imbuída em tais ações é, então, a associação da Educação Física ao fenômeno esportivo a partir de uma visão hegemônica de esporte na nossa cultura. O que, por sua vez, guarda pouca coerência teórico-metodológica, ética e política com o discurso adotado pelo próprio Ministério do Esporte quanto à ênfase na ideia da inclusão social.

Isso porque, conforme Chaves (2005), tais ação congregam um entendimento de esporte que - independentemente do lugar em que esteja inserido - se traduz exclusivamente em rendimento, performance, desempenho, competição, vitória e recordes. O conceito de talento esportivo, ademais, está baseado apenas numa concepção biologicista de crianças e jovens, sem se atentar para os fatores socioambientais e culturais que são o fulcro do desenvolvimento das práticas esportivas nessa faixa etária.

\section{ESPORTE DA ESCOLA}

O programa Esporte da Escola foi criado em 2007 a partir da articulação entre o programa Mais Educação (PME), do Ministério da Educação (MEC), e o programa Segundo Tempo, do Ministério do Esporte (ME). O primeiro almejava ampliar o tempo de permanência dos alunos nas escolas e o segundo buscava democratizar o acesso à prática esportiva nas escolas públicas.

Nesses termos, tal articulação forjou um programa de esporte da escola cujos objetivos envolviam a promoção da inclusão, minimizando as desigualdades e qualquer tipo de discriminação por condições físicas, sociais, de raça, de cor ou de qualquer natureza que limitassem o acesso à prática esportiva; o oferecimento de conhecimentos e vivências da prática esportiva nas dimensões lúdica e inclusiva; a ampliação do tempo de permanência dos alunos na escola; o fortalecimento de hábitos e valores que incrementassem a formação da cidadania dos alunos; a ampliação do conhecimento dos alunos sobre a prática esportiva e suas relações com a cultura, educação, saúde e vida ativa; e, por fim, a contribuição para a melhoria da qualidade da Educação Básica. 
Para tanto, suas orientações e princípios teórico-metodológicos ansiavam pela construção de uma relação pedagógica centrada no processo de escolarização das práticas corporais. Assim, defendiam que a seleção dos conteúdos deveria emergir do conhecimento da cultura corporal universal, relacionada, sobretudo, à sua significação humana e social. Além disso, asseveravam pela compreensão dos determinantes sócio-históricos do aluno, particularmente de sua condição de classe social. Desse modo, o conhecimento da prática esportiva deveria informar ao aluno sobre os acontecimentos nacionais e internacionais atualizados, bem como sobre o avanço da ciência e da técnica. Por isso, a prática esportiva deveria propiciar a ampliação do acervo da cultura corporal das crianças e dos adolescentes, mantendo a ludicidade como seu traço essencial.

Os aportes teórico-metodológicos que fundamentam tais diretrizes decorrem, portanto, de uma pedagogia de natureza crítica que, no âmbito da Educação Física, foi sistematizada, sobremaneira, a partir da década de 1980 por ocasião dos movimentos de renovação dos matizes teórico-conceituais e teóricometodológicos da área.

Nessa direção, a opção do programa pela cultura corporal representou um entendimento afinado às teorias pedagógicas de natureza crítica da Educação Física/Ciências do Esporte. Isso justifica, pois, orientações e princípios teóricometodológicos que parametrizavam as ações do programa. . Nesse sentido, o programa acabava por reafirmar o princípio da contemporaneidade do conteúdo, já que assumia a função de assegurar o acesso ao que de mais avançado se produziu, técnica e cientificamente, no âmbito da cultura corporal, seja nacional ou internacionalmente.

Além disso, o programa admitia a necessidade de a escola sustentar o desenvolvimento e a democratização do conhecimento esportivo, bem como a apreensão da realidade social complexa. Dessa maneira, o Esporte da Escola assumiu a função de inteligibilidade do real, condição pela qual os sujeitos podiam localizar-se no mundo, dominá-lo e entender suas necessidades. (MARTINS, 2011).

O programa elegeu, ademais, a ludicidade como traço fundamental das práticas corporais, o que, segundo Oliveira (2001, p. 199-200), constitui ponto crucial na perspectiva de "reinvenção do esporte". Isso porque a ludicidade representa um passo importante para romper com a separação absoluta entre jogo e esporte. Ou seja, para se "[...] brincar de esportes, para tornar lúdica a tensão do esporte, para transformar o compromisso com a vitória em compromisso a alegria e o prazer para todos".

Pelo apresentado, a escolha do nome do programa não parece arbitrária ou mesmo despótica, haja vista toda a carga semântica que o acompanha. Assim, seu nome sugere a incorporação de um debate a muito latente na Educação 
Física/Ciências do Esporte e que se traduz na alardeada disjuntiva "esporte na/da escola".

Entretanto, em 2014, o programa lançou uma coleção de livros que o distanciava desse paradigma teórico-metodológico. Os materiais voltados à orientação da prática pedagógica reuniam, inicialmente, quatro livros que se dedicavam a discutir e propor atividades para o programa. Nesse material, o professor deveria organizar a apropriação dos saberes da cultura corporal considerando suas dimensões conceituais, procedimentais e atitudinais, já que:

Tais conteúdos não devem ser ensinados e aprendidos pelos alunos apenas na dimensão do saber fazer [procedimental], mas devem incluir um saber sobre esses conteúdos [conceitual] e um saber ser e se relacionar [atitudinal], de tal modo que possa efetivamente garantir a sua função cidadã. (GONZÁLEZ; DARIDO; OLIVEIRA, 2014 , p. 16, grifos dos autores).

Para tanto, tal proposta advogava a articulação/integração entre as dimensões conceitual, procedimental e atitudinal numa tentativa de apreensão global dos conteúdos. Nesses termos, o tom progressista - presente nos princípios metodológicos - não encontrava correspondente nas novas orientações técnicooperacionais. Em seu lugar figurava valores político-educacionais balizados, fundamentalmente, pelos quatro pilares da educação no século XXI: aprender a conhecer, a fazer, a viver juntos e a ser. (DELORS, 1998).

O que representa, em última análise, um raciocínio calçado na busca de equilíbrio e conciliação entre polos opostos. Nesse sentido, à educação, ao esporte e às demais práticas corporais foram colocados, o papel de esconder as contradições do projeto neoliberal de sociedade, isto é, as contradições que atravessam o capitalismo contemporâneo.

Pelo apresentado, o Esporte da Escola, ao incorporar o discurso que consta no relatório (DELORS, 1998) não só contradiz seus princípios metodológicos, mas também delega ao esporte um papel importante na preparação de um trabalhador mais adequado aos novos padrões de exploração e, também, na difusão de novos modos de ser amplamente conformados com a dominação burguesa.

Em que pese os desencontros entre o modelo lógico-conceitual e o técnicooperacional do Esporte da Escola, é nítida sua vinculação com o projeto de formação em curso nas escolas brasileiras. Projeto este que, conforme Saviani (2007), tem sido conduzido por uma espécie de 'pedagogia de resultados'. 


\section{CONSIDERAÇÕES FINAIS}

Esse texto buscou apreciar criticamente os princípios teórico-metodológicos dos programas de esporte educacional organizados pelos Governos Lula e Dilma entre os anos de 2003 e 2016. Para tanto, foram avaliadas as diretrizes teóricometodológicas do PST, da Ação Descoberta do Talento Esportivo, do Projeto Esporte Brasil e do Esporte da Escola, isto é, os programas que ofereceram a seus agentes culturais orientações para o trato didático-pedagógico do esporte.

A análise sugere um conjunto de avanços, limites e anacronismos. Desses limites, destaca-se a ausência de coerência lógico-epistemológica. O que revela, no conjunto, falta de organização e definição da linha de ação governamental das políticas de esporte educacional em análise. O que produz, consequentemente, descompassos importantes entre os programas e o discurso encampado pelo próprio Ministério do Esporte, sobretudo no tocante à formação cidadã e inclusão social, bem como distorções substantivas entre o papel da escola no processo de escolarização das práticas esportivas.

A despeito dessa falta de organicidade e dos problemas daí decorrentes, há avanços significativos no conjunto dessa produção, os quais envolvem: a defesa, sempre pertinente, da democratização da cultura esportiva e do esporte como um direito; a presença de um entendimento que reconhece a necessidade de construção de um "jeito particular" ou forma escolar para o esporte educacional; a ideia de que o esporte educacional constitui um elemento importante na experiência humana; e a ênfase nos princípios da inclusão - vinculada à perspectiva da diversidade de corpos, etnia, habilidades, gênero e sexualidade, em outros termos, da relação social com o corpo e com a diferença. Além do foco na ludicidade como aspecto para a reinvenção do esporte nos sistemas formais de ensino.

Apesar dos avanços, há, no conjunto das políticas esportivas de conteúdo educacional analisado, limites de natureza teórico-metodológicas importantes, os quais abrangem a ênfase/centralidade do paradigma esportivo e da aptidão física/aprendizagem motora no processo de apropriação do esporte. Aspecto que implica num processo de ensino-aprendizagem pautado exclusivamente nos saberes técnico e tático. $\mathrm{E}$, também, na compartimentalização dos saberes que responde pela totalidade do fenômeno esportivo. O que supõe desarticular a ação (o que se faz), do pensamento sobre ela (o que se pensa) e do sentido que ela tem (o que se sente).

Além disso, tal orientação pedagógica responde pela adoção de uma visão fragmentada de homem dada a necessidade de respostas às dimensões cognitiva, motora e afetiva. Ademias, a perspectiva de colonização do esporte educacional 
pelos sentidos, valores e regras do esporte de rendimento representa uma subordinação incoerente com as funções da escola no processo de democratização e escolarização da cultura esportiva.

Além dos avanços e limites, há elementos "fora do tempo e do lugar", isto é, anacrônicos. Os quais expressam a falta de alinhamento, consonância e correspondência com os anseios e perspectivas colocadas naquele contexto para a operacionalização/materialização das políticas de esporte educacional em governos de viés popular.

Argumento que pode ser comprovado a partir do reclame para que a Educação Física e, consequentemente, a escola participe da seleção, identificação, orientação e formação de novos talentos esportivos, operando, assim, como a base do sistema esportiva nacional, como outrora. Nesse sentido, dois programas merecem atenção especial: a Ação Descoberta do Talento Esportivo e o Projeto Esporte Brasil. Os quais sugerem, indiscutivelmente, a participação dos professores de Educação Física e da escola em competições cuja finalidade última seria a produção de esportistas com condições/potenciais para o rendimento. Fato que ocorre em detrimento da celebração, do convívio e da participação lúdica, crítica e criativa que a prática esportiva escolar pode proporcionar.

É imprescindível, então, reconhecer que, numa perspectiva de conjunto, esses dois programas concorrem para viabilizar a articulação entre as demais políticas de esporte educacional e o sistema esportivo stricto senso. Mesmo porque funcionam como uma peneira que permite a "transição" do esporte educacional para o esporte de rendimento.

Assim, advoga-se que o esporte precisa ser objeto de reflexão e apropriação pedagógica, seja por meio das aulas de Educação Física ou mesmo como objeto de políticas esportivas educacionais. Um elemento da cultura corporal que precisa ser apreendido, demandando estrutura e organização pedagógica que viabilize seu entendimento, apreensão, reflexão e reconstrução como conhecimento que constitui o acervo cultural da humanidade - aspectos que implicam a construção de uma forma educacional para o esporte no Brasil.

Por fim, para dar conta desses desafios é fundamental o desenvolvimento de novos estudos que aprofundem a análise dos programas esportivos em curso no país, a fim de construir referenciais para o estabelecimento de políticas públicas comprometidas com a equidade e justiça social, pautadas em uma concepção de esporte e educação como elementos da prática social, pedagógica, cultural e política. 


\section{FinANCIAMENTO}

O presente trabalho foi realizado com apoio da Coordenação de Aperfeiçoamento de Pessoal de Nível Superior - Brasil (CAPES) - Código de Financiamento 001.

\section{NOTAS}

\section{CONFLITOS DE INTERESSE}

Os autores não têm conflitos de interesse, incluindo interesses financeiros específicos e relacionamentos e afiliações relevantes ao tema ou materiais discutidos no manuscrito.

\section{Autoria e CoAutoria}

Os autores declaram que participaram de forma significativa na construção e formação desde estudo, tendo responsabilidade pública pelos conteúdos deste, pois contribuíram diretamente para o desenvolvimento intelectual deste trabalho e satisfazem as exigências de autoria.

Nadson Santana Reis - Concepção e desenvolvimento (desde a ideia para a investigação ou artigo, criou a hipótese); Desenho metodológico (planejamento dos métodos para gerar os resultados); Supervisão (responsável pela organização e execução do projeto e da escrita do manuscrito); Coleta e tratamento dos dados (responsável pelos experimentos, pacientes, organização dos dados); Análise / interpretação (responsável pela análise estatística, avaliação e apresentação dos resultados); Levantamento da literatura (participou da pesquisa bibliográfica e levantamento de artigos); Redação (responsável por escrever uma parte substantiva do manuscrito).

Pedro Fernando Avalone de Athayde - Concepção e desenvolvimento (desde a ideia para a investigação ou artigo, criou a hipótese); Desenho metodológico (planejamento dos métodos para gerar os resultados); Supervisão (responsável pela organização e execução do projeto e da escrita do manuscrito); Análise / interpretação (responsável pela análise estatística, avaliação e apresentação dos resultados); Revisão crítica (responsável pela revisão do conteúdo intelectual do manuscrito antes da apresentação final).

Fernando Mascarenhas - Concepção e desenvolvimento (desde a ideia para a investigação ou artigo, criou a hipótese); Desenho metodológico (planejamento dos métodos para gerar os resultados); Supervisão (responsável pela organização e execução do projeto e da escrita do manuscrito); Análise / interpretação (responsável pela análise estatística, avaliação e apresentação dos resultados); Revisão crítica (responsável pela revisão do conteúdo intelectual do manuscrito antes da apresentação final). 


\section{REFERÊNCIAS}

ANVERSA, Ana Luiza Barbosa et al. Formação continuada na implementação do esporte educacional na educação física escolar. Pensar a Prática, Goiânia, v. 21, n. 4, p. 845-853, out./dez. 2018.

BEHRING, Elaine; BOSCHETTI, Ivanete. Política social: fundamentos história. 9. ed. São Paulo: Cortez, 2011.

BOSCHETTI, Ivanete. Avaliação de políticas, programas e projetos sociais. In: CFESS/ABEPSS. Serviço social: direitos sociais e competências profissionais. Brasília: CFESS, ABEPSS, 2009.

BRACHT, Valter. Sociologia crítica do esporte: uma introdução. Vitória: UFES, Centro de Educação Física e Desportos, 1997.

BRACHT, Valter; ALMEIDA, Felipe. Esporte, escola e a tensão que os megaeventos trazem para a Educação Física Escolar. Em Aberto, Brasília, v. 26, n. 89, p. 131-143, jan./jun. 2013.

BRASIL. Casa Civil. Decreto no. 7.984 de 08 de abril de 2013. Disponível em: http://www.planalto.gov.br/ccivil 03/ ato2011-2014/2013/decreto/d7984.htm. Acesso em: 20 abr. 2021.

BRASIL. Casa Civil. Lei 9.615 de 24 de março de 1998 (Lei Pelé). Disponível em: http://www.planalto.gov.br/ccivil 03/leis/19615consol.htm. Acesso em: 12 set. 2020.

BRASIL. Ministério da Cidadania. Cartilha Descoberta do Talento Esportivo. 2004. Disponível em: http://www2.esporte.gov.br/arquivos/snear/talentoEsportivo/cartilha.pdf. Acesso em: 13 abr. 2021.

BRASIL. Ministério da Cidadania. Manual de orientações Esporte na Escola. 2013. Disponível em: http://www.esporte.gov.br/arquivos/snelis/segundoTempo/maisEducacao/MANUAL DE ORIENTAES - ESPORTE NA ESCOLA 2013.pdf. Acesso em: 23 abr. 2021.

BRASIL. Ministério da Cidadania. Programa Segundo Tempo: Diretrizes 2014. Brasília, 2014. Disponível em:

http://www.esporte.gov.br/arquivos/snelis/segundoTempo/Diretrizes\%20PST\%20\%20Padro\%202014.pdf. Acesso em: 20 de abr. 2021.

BRASIL. Ministério da Educação. Portaria Interministerial no 17 de 24 de Abril de 2007 (Institui o Programa Mais Educação). Disponível em:

http://portal.mec.gov.br/arquivos/pdf/mais educacao.pdf. Acesso em: 23 abr. 2021.

BRASIL. Ministério do Esporte - Secretaria Nacional de Esporte Educacional. Material didático para o processo de capacitação do Programa Segundo Tempo. Brasília, 2008.

BRASIL. Ministério da Educação. Programa Mais Educação: passo a passo. Brasília, 2009. Disponível em: http://portal.mec.gov.br/dmdocuments/passoapasso maiseducacao.pdf. Acesso em: 23 abr. 2021.

CARNEIRO, Fernando Henrique Silva; MASCARENHAS, Fernando; MATIAS, Wagner Barbosa. O esporte educacional na educação de tempo integral: o plano nacional de educação 2014-2024. Caderno de Educação Física e Esporte, Marechal Cândido Rondon, v. 15, n. 2, p. 25-36, jul./dez. 2017. 
CASTELLANI FILHO, Lino. A Educação Física no sistema educacional brasileiro: percurso, paradoxos e perspectivas. 1999. 189 f. Tese (Doutorado em Educação) - Faculdade de Educação, Universidade Estadual de Campinas, Campinas, 1999.

CASTELLANI FILHO, Lino. Lazer, cultura e educação: reflexões nada aleatórias sob a ótica da educação física. In: MASCARENHAS, Fernando; LAZZAROTI FILHO, Ari. Lazer, cultura e educação: contribuições ao debate contemporâneo. Goiânia: Editora UFG, 2010.

CASTRO, Suélen Barboza Eiras; SCARPIN, Jorge Eduardo; SOUZA, Doralice Lange. Financiamento público e esporte educacional: uma análise do processo orçamentário do programa "Segundo Tempo" (2004-2011). Motrivivência, Florianópolis, v. 29, n. 52, p. 136-156, set., 2017.

CHAVES, Renata Barcelos. Ação "Descoberta do Talento Esportivo": o que está por trás de tudo isto? 2005. Trabalho de Conclusão de Curso (Graduação em Educação Física) Centro de Desportos, Universidade Federal de Santa Catarina, Florianópolis, 2005.

SOARES, Carmen Lúcia SOARES et al. Metodologia do ensino de educação física. São Paulo: Cortez, 1992.

DELORS, Jacques (Org.). Educação: um tesouro a descobrir. São Paulo: Cortez, 1998.

DUARTE, Newton. Vigotski e o "aprender a aprender": críticas às apropriações neoliberais e pós-modernas de teoria vigotskiana. 4. ed. Campinas: Autores Associados, 2006.

GAYA, Adroaldo. PROESP-BR Projeto Esporte Brasil. Indicadores de saúde e fatores de prestação esportiva em crianças e jovens. CENESP-UFRGS, [ca. 2002]. Disponível em: https://www.proesp.ufrgs.br/. Acesso em: 13 mar. 2021.

GONZÁLEZ, Fernando Jaime; DARIDO, Suraya Cristina; OLIVEIRA, Amauri Aparecido Bássoli. (Orgs.). Esporte de invasão: basquetebol, futebol, handebol, ultimate frisbee. Maringá: Editora Eduem, 2014.

GRECO, Pablo Juan; CONTI, Gustavo; MORALES, Juan Carlos Pertez. (Orgs.). Manual de práticas para a iniciação esportiva no Programa Segundo Tempo. Maringá: Eduem, 2013.

GRECO, Juan Greco; SILVA, Siomara. A metodologia de ensino dos esportes no marco do Programa Segundo Tempo. In: BRASIL. Ministério do Esporte - Secretaria Nacional de Esporte Educacional. Material didático para o processo de capacitação do Programa Segundo Tempo. Brasília, 2008.

GRECO, Juan Greco; SILVA, Siomara; SANTOS, Lucídio Rocha. Organização e desenvolvimento pedagógico do esporte no Programa Segundo Tempo. In: OLIVEIRA, Amauri Aparecido Bássoli; PERIM, Gianna Lepre. (Orgs.). Fundamentos Pedagógicos do Programa Segundo Tempo: da reflexão à prática. Maringá: Eduem, 2009.

KRAVCHYCHYN, Claudio; OLIVEIRA, Amauri Aparecido Bássoli. Esporte educacional no Programa Segundo Tempo: uma construção coletiva. Journal of Physical Education, Maringá, v, 27, e2719, p. 01-18, 2016.

KUNZ, Elenor. Transformação didático-pedagógico do Esporte. Inijuí: UNIJUÍ, 1994.

KUNZ, Elenor. Esporte: uma abordagem com a fenomenologia. In: STIGGER, Marco Paulo; LOVISOLO, Hugo. (Orgs.). Esporte de rendimento e esporte na escola. Campinas: Autores Associados, 2009. 
LIBÂNEO, José Carlos. Democratização da escola pública: a pedagogia crítico-social dos conteúdos. São Paulo, Loyola, 1985.

MACHADO, Gisele Viola et al. A análise da evolução das políticas públicas em esporte educacional no Brasil. Revista Ciências Humanas - Educação e Desenvolvimento Humano, Taubaté, v. 10, n. Extra, ed. 19, p. 103-115, Out. 2017.

MARTINS, Lígia Márcia. Pedagogia histórico-crítica e psicologia histórico-cultural. In: MARSIGLIA, Ana Carolina Galvão. (Org.). Pedagogia histórico-crítica: 30 anos. Campinas: Autores Associados, 2011.

MASCARENHAS, Fernando. Megaeventos esportivos e educação física: alerta de tsunami. Movimento, Porto Alegre, v.18, n.1, p. 39-67, jan./mar. 2012.

OLIVEIRA, Sávio Assis. A reinvenção do esporte: possibilidades da prática pedagógica. Campinas: Autores Associados, 2001.

OLIVEIRA, Sávio Assis. O 'novo' interesse esportivo pela escola e as políticas públicas nacionais. 2009. 353 f. Tese (Doutorado em Educação) - Centro de Educação, Universidade Federal de Pernambuco. Recife, 2009.

PAES, Viviane Ribeiro; AMARAL, Silvia Cristina Franco. Políticas públicas de esporte educacional em São Paulo: impactos dos Jogos Olímpicos de 2016. Movimento, Florianópolis, v. 23, n. 2, p. 715-728, abr./jun. 2017.

PERIM, Gianna Lepre; OLIVEIRA, Amauri Aparecido Bássoli. Apresentação. In: OLIVEIRA, Amauri Aparecido Bássoli; PERIM, Gianna Lepre. (Orgs.). Fundamentos Pedagógicos do Programa Segundo Tempo: da reflexão à prática. Maringá: Eduem, 2009.

PIRES, Giovani Lorenzi; SILVEIRA, Juliano. Esporte educacional... existe? Tarefa e Compromisso da Educação Física com o esporte na escola. In: SILVA, Maurício Roberto. (Org.) Esporte, educação, estado e sociedade: as políticas públicas em foco. Chapecó: Argos, 2007.

REIS, Nadson Santana. Políticas de esporte educacional nos governos Lula e Dilma: avanços, limites e anacronismos. 2015. 200 f. Dissertação (Mestrado em Educação Física) - Faculdade de Educação Física. Universidade de Brasília. Brasília, 2015.

Reis, Nadson Santana, et al. O esporte educacional como tema da produção de conhecimento no periodismo científico brasileiro: uma revisão sistemática. Pensar a Prática, Goiânia, v. 18, n. 3, p. 709-724, jul./set. 2015.

ROTTMANN, Hans Gert; RATTO, Cleber Gibbon. Educação Física: repensando práticas pedagógicas, sociabilidades e esporte na cultura contemporânea. Práxis Educacional, Vitória da Conquista, v. 14, n. 28, p. 378-397, 2017.

SANTOS, Edmilson Santos; NOGUEIRA, Rafaela Cristina Amaral. Avaliação da política pública de esporte educacional: o caso do Programa Segundo Tempo/ME na Região Sul da Bahia. Revista Interdisciplinar De Gestão Social, Salvador, v.5, n.1 p. 89-105, jan./abr. 2016.

SAVIANI, Dermeval. O Plano de Desenvolvimento da Educação: análise do projeto do MEC. Revista Educação e Sociedade, Campinas, v. 28, n. 100 - Especial, p. 1231-1255, out. 2007. 
SILVA, Patrícia da Rosa Louzada et al. Formação continuada de professores e a aplicabilidade dos princípios pedagógicos do esporte educacional. Revista Humanidades e Inovação, Palmas, v. 07, n. 10, p. 169-185, 2020.

SOUZA, Mauro José de. Saberes e práticas educativas: hibridismos presentes nas relações entre esporte educacional e performance esportiva. Revista Humanidades e Inovação, Palmas, v. 06, n. 06, p. 62-73, 2019.

Recebido em: 08 jul. 2021 Aprovado em: 08 out. 2021

Artigo submetido ao sistema de similaridade Turnitin $®$.

A revista Conexões utiliza a Licença Internacional Creative Commons Atribuição 4.0, preservando assim, a integridade dos artigos em ambiente de acesso aberto.

A Revista Conexões é integrante do Portal de Periódicos Eletrônicos da Unicamp e associado/membro das seguintes instituições:

ABEC

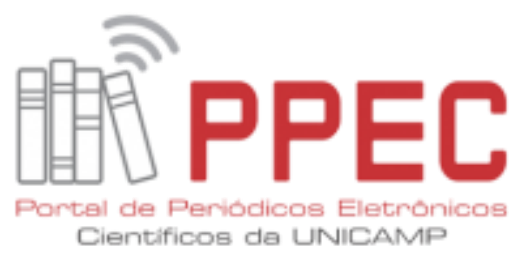

